\title{
Thermal Stability of Interspecies Neisseria DNA Duplexes
}

\author{
By D. T. KINGSBURY,* G. R. FANNING, K. E. JOHNSON \\ AND D. J. BRENNER \\ Department of Microbiology, Naval Medical Research Institute, \\ Bethesda, Md. 20014, and Division of Biochemistry, Walter Reed Army \\ Institute of Research, Washington, D.C. $200 \mathrm{I} 2$, U.S.A.
}

(Accepted for publication 23 September 1968)

\section{SUMMARY}

The thermal stability of interspecies DNA duplexes is markedly increased by raising the incubation temperature. When the DNA reassociation reactions are carried out at $75^{\circ}$ in $0 . \mathrm{I} 2 \mathrm{M}$-phosphate buffer the thermal denaturation temperature of the reassociated product is almost identical to that of the native DNA, indicating that only DNA segments of very similar nucleotide sequence are associating. The genus Neisseria very clearly forms three groups based on the relatedness of their DNA to that of $N$. meningitidis; the 'pathogenic' Neisseria which have at least $80 \%$ of their nucleotide sequences similar; the 'non-pathogenic' Neisseria which share only 8 to $15 \%$; and $N$. catarrhalis which shows no relatedness.

\section{INTRODUCTION}

The usefulness of DNA-DNA hybridization procedures in studying taxonomic relationships has been clearly demonstrated in many groups of bacteria (McCarthy \& Bolton, 1963; Brenner, Martin \& Hoyer, 1967; Kingsbury, 1967; Heberlein, De Ley \& Tijtgat, I967; Hoyer \& McCullough, I968; Johnson \& Ordal, 1968). Recently, thermal stability has been used to investigate the extent of base pairing within reassociated interspecies polynucleotide sequences (Brenner \& Cowie, I967, 1968). The importance of incubation temperature in discriminating between distantly and closely related DNA sequences has been shown in several laboratories (Martin \& Hoyer, I966; Brenner et al. 1967; Brenner \& Cowie, 1967, 1968; Johnson \& Ordal, 1968). The experiments reported here utilized increased incubation temperature and studies of thermal stability to further assess previously determined relationships within the genus Neisseria (Kingsbury, 1967).

DNA relationships among the Neisseria are of particular interest since both pathogens and non-pathogens, as well as several tentatively assigned organisms, are included in this genus (Kingsbury \& Ivler, to be published). Earlier work (Kingsbury, 1967) indicated that the Neisseria species form at least three distinct groups: the 'pathogenic' Neisseria, the 'non-pathogenic' Neisseria and the species $N$. catarrhalis and $N$. caviae. A similar view, based on genetic transformation studies in this genus, has been advanced by Henriksen \& Bøvre (1968). The present study, using $N$. meningitidis as the reference organism, reaffirms this division of the genus Neisseria into three groups. Furthermore, the extensive duplex formation and the stability of reassociated nucleo-

* Present address: Department of Biology, University of California (San Diego), La Jolla, California 92037 . 
tide sequences shared between $N$. meningitidis, $N$. gonorrhoeae and strain z (Slaterus, 196I) are indicative of extensive conservation of nucleotide sequences in the DNA of these pathogens.

\section{METHODS}

Organisms. The source of each strain used in this study and the procedures used for identification and cultivation have been described (Kingsbury, 1966, 1967).

Enzymes and radioisotopes. Ribonuclease and Pronase were purchased from Calbiochem, Los Angeles, California, U.S.A. The Pronase, in distilled water, was selfdigested by incubation for $2 \mathrm{hr}$ at $37^{\circ}$ prior to use. Ribonuclease was heated at $90^{\circ}$ for IO min. to inactivate any deoxyribonuclease present as a contaminant. Adenine- $8-{ }^{14} \mathrm{C}$ was purchased from Calbiochem. ${ }^{32} \mathrm{P}$ in the form of carrier-free $\mathrm{H}_{2} \mathrm{PO}_{4}$ was obtained from New England Nuclear Corporation, Boston, Massachusetts, U.S.A.

DNA extraction. Organisms were harvested from broth by centrifugation and washed in $150 \mathrm{ml}$ of $0.15 \mathrm{M}-\mathrm{NaCl}+0 . \mathrm{I} \mathrm{M}-\mathrm{EDTA}, \mathrm{pH} 8 \cdot 0$. Organisms were lysed and DNA prepared as previously described (Brenner \& Cowie, 1968). The crude DNA preparations were repeatedly ( 3 to 4 times) precipitated with cold $95 \%$ ethanol and resuspended in $\mathrm{SSC} / \mathrm{IO0}(\mathrm{SSC}=0.15 \mathrm{M}-\mathrm{NaCl}+0.015 \mathrm{M}$-sodium citrate; $3 \times \mathrm{SSC}$ is used to designate a threefold concentration). The DNA preparations were resuspended in a mixture of $0.1 \mathrm{M}-\mathrm{NaCl}, 0.05 \mathrm{M}$-EDTA and $0.5 \mathrm{M}$-tris buffer, and incubated with ribonuclease $25 \mu \mathrm{g} . / \mathrm{ml}$. at $37^{\circ}$ for $60 \mathrm{~min}$. Sodium lauryl sulphate was added to $0.5 \%$ and the DNA was incubated overnight at $37^{\circ}$ with $50 \mu \mathrm{g} / \mathrm{ml}$ of Pronase. The concentration of sodium lauryl sulphate was increased to $\mathrm{I} \%$ and an equal volume of water-washed phenol was added. The mixture was shaken and centrifuged. The aqueous phase was collected and shaken twice with an equal volume of chloroform. The aqueous phase was then repeatedly ( 3 to 4 times) precipitated with 2 vol. of 2-ethoxyethanol. The DNA was finally resuspended in $0.12 \mathrm{M}-\mathrm{PB}(\mathrm{PB}=\mathrm{a}$ buffer solution consisting of equimolar $\mathrm{Na}_{2} \mathrm{HPO}_{4}$ and $\mathrm{NaH}_{2} \mathrm{PO}_{4}, \mathrm{pH}=6 \cdot 8$ ).

DNA samples (except those unlabelled samples which were subsequently bound to nitrocellulose filters) were fragmented by mechanical shear at 50,000 p.s.i. to a molecular weight of approximately $2 \times 10^{5}$ (Britten \& Kohne, 1966) and filtered through Metrical filter discs $(0.45 \mu$ pore size, Gelman Instrument Company, Ann Arbor, Michigan, U.S.A.). Labelled single-stranded DNA fragments in 0.12 M-PB were further purified by passing them through a hydroxyapatite (Bio-Gel HT, Bio-rad Laboratories, Richmond, California, U.S.A.) column at $60^{\circ}$ and discarding the material that bound to the column. (Single-stranded DNA does not bind to the column under these conditions.)

Preparation of labelled $D N A .{ }^{14} \mathrm{C}$-labelled DNA was prepared as previously described (Kingsbury \& Duncan, 1967 ). ${ }^{32} \mathrm{P}$ labelling was accomplished by growing the bacteria in Frantz broth containing $5 \mu \mathrm{c} / \mathrm{ml}$. of carrier-free $\mathrm{H}_{2} \mathrm{PO}_{4}$ and $0.00 \mathrm{I}$ M-unlabelled phosphate.

Formation of DNA hybrids on nitrocellulose filters. The hybridization procedures used for nitrocellulose filter reactions have been described (Kingsbury, 1967). In the present studies only direct binding experiments were carried out. In each case $125 \mu \mathrm{g}$. of DNA was immobilized on a $25 \mathrm{~mm}$. B-6 filter (Schleicher and Schuell Company, Keene, New Hampshire, U.S.A.) and incubated with I $\mu \mathrm{g}$. of ${ }^{14} \mathrm{C}$-labelled DNA fragments.

Thermal elution of reassociated DNA duplexes from hydroxyapatite. A modification of the technique of Miyazawa \& Thomas (1965) for fractionating double-stranded 
DNA bound to hydroxyapatite was used to determine the stability of reassociated Neisseria DNA (Britten \& Kohne, I966). Thermally denatured ${ }^{32}$ P-labelled N. meningitidis DNA fragments ( $0.1 \mu \mathrm{g}$., containing 2000 to 5000 counts $/ \mathrm{min}$.) were incubated at $60^{\circ}$ or $75^{\circ}$ with an approximate $5000-$ fold excess of homologous or heterologous denatured, unlabelled DNA fragments in I ml. of $0.12 \mathrm{M}-\mathrm{PB}$. The duration of incubation ( $12 \mathrm{hr}$ ) was chosen to insure maximal reassociation of the unlabelled DNA fragments. The 'zero-time' binding (the amount of labelled DNA bound to hydroxyapatite immediately after denaturation) was between $\mathrm{I}$ and $2 \%$. The control values obtained for reassociation of labelled fragments with one another during the $\mathrm{I} 2 \mathrm{hr}$ incubation period were between 2 and $4 \%$.

Following incubation, samples were quickly cooled and frozen until use. Each sample was subsequently thawed and passed through io $\mathrm{ml}$. of hydroxyapatite equilibrated with $0.12 \mathrm{M}$-PB at the temperature at which the fragments had been incubated. The earlier hydroxyapatite experiments used water-jacketed columns. Later experiments employed a batch procedure for thermal elution which allowed six or more samples to be processed simultaneously. In the batch procedure reaction mixtures were added to $\mathrm{Io} \mathrm{ml}$. of hydroxyapatite contained in test tubes in a circulating water bath. Elutions were accomplished by sedimenting the tubes in a heated centrifuge. The details of the batch procedure are given elsewhere (Brenner, Fanning, Rake \& Johnson, private communication). Virtually identical results were obtained with either the column or batch procedure. Each sample was washed with $15 \mathrm{ml}$. portions of $0.12 \mathrm{M}-\mathrm{PB}$ until the eluted radioactivity (representing unreassociated DNA not bound to hydroxyapatite) was down to a background level (5-6 washes). The hydroxyapatite-bound DNA was then consecutively washed with I $5 \mathrm{ml}$. portions of $0.12 \mathrm{M}-\mathrm{PB}$ at increasing $2 \cdot 5^{\circ}$ temperature increments to $100^{\circ}$ and finally with $2-3,15 \mathrm{ml}$. portions of $0.4 \mathrm{M}$-PB to elute any material remaining bound to the column. When the elution temperature was raised above the dissociation temperature of the reassociated nucleotide sequences, the resultant single-stranded DNA was eluted from the column.

The contents of the elution tubes were precipitated in $5 \%$ trichloracetic acid in the presence of approximately $100 \mu \mathrm{g}$. of yeast ribonucleic acid carrier. The precipitates were collected on membrane filters, dried, and placed in counting vials. Scintillation fluid was added ( $5 \mathrm{ml}$. per sample) and the samples were counted in either a Packard (Packard Instrument Company, Downers Gove, Illinois, U.S.A.) or a Nuclear Chicago (Nuclear-Chicago Corporation, Des Plaines, Illinois, U.S.A.) liquid scintillation spectrometer. Percentage reassociation was determined by dividing the counts present in the thermal elution by the total counts.

\section{RESULTS}

Effect of temperature on DNA-DNA reassociation. The effect of different incubation temperatures on interspecies DNA reassociation is shown in Table I. When the incubation temperature was raised from $60^{\circ}$ to $75^{\circ}$, the reassociation of homologous Neisseria meningitidis DNA dropped some $5-8 \%$ (the term reassociation is applied to both the homologous and heterologous reactions although the interspecies strands had never before been associated). The relative ability of $N$. meningitidis DNA fragments to reassociate with DNA from $N$. gonorrhoeae or strain $\mathrm{z}$ was only slightly diminished at the more stringent $75^{\circ}$ incubation temperature. (Relative binding is used to compare the interspecies reactions with the homologous reaction under the identical 
incubation conditions. In every case, the homologous $N$. meningitidis reaction is arbitrarily designated $100 \%$.) Relatedness between $N$. meningitidis and $N$. flava was diminished more than twofold and between $N$. meningitidis and $N$. sicca was diminished more than fivefold when the criterion was changed to the high temperature of incubation. There was very little relatedness between $N$. meningitidis and $N$. catarrhalis at $60^{\circ}$. At $75^{\circ}$, no reaction was detectible between the DNA of these organisms.

As the ionic strength was raised, the effective temperature of incubation was lowered. Sodium ion concentration was similar in $0.12 \mathrm{M}-\mathrm{PB}$ and SSC. The three-fold increase in ionic strength from $0.12 \mathrm{M}-\mathrm{PB}$ to $3 \times \mathrm{SSC}$ resulted in a 5 to $6^{\circ}$ decrease in effective incubation temperature (Marmur \& Doty, I962). Therefore, when the incubation is done at $67^{\circ}$ in $3 \times \mathrm{SSC}$, the extent of the reaction should be similar to that occurring at $60^{\circ}$ in PB. The data presented in the last column of Table I show this to be true.

Table I. Relatedness of the DNA extracted from Neisseria species

\begin{tabular}{|c|c|c|c|c|c|}
\hline \multirow{3}{*}{$\begin{array}{c}\text { Source of unlabelled } \\
\text { DNA }\end{array}$} & \multicolumn{5}{|c|}{ Relative relatedness to labelled $N$. meningitidis DNA* } \\
\hline & \multicolumn{2}{|c|}{$\begin{array}{l}60^{\circ} \text { Incubation } \\
(0.12 \mathrm{M}-\mathrm{PB})\end{array}$} & \multicolumn{2}{|c|}{$\begin{array}{l}75^{\circ} \text { Incubation } \\
(0.12 \mathrm{M}-\mathrm{PB})\end{array}$} & \multirow{2}{*}{$\begin{array}{c}67^{\circ} \text { Incubation } \\
(3 \times \text { SSC }) \\
\%\end{array}$} \\
\hline & $\%$ & $\operatorname{Tm} \dagger$ & $\%$ & $\operatorname{Tm}$ & \\
\hline$N$. meningitidis & $(100) \ddagger$ & 87 & $(100)$ & 88 & $(100)$ \\
\hline$N$. gonorrhoeae & 78 & 85 & 76 & 86 & 80 \\
\hline Strain $\mathrm{Z}$ & 88 & 87 & $8 \mathrm{I}$ & 87 & 89 \\
\hline N. sicca & 45 & 77 & 8 & 86 & 45 \\
\hline N. flava & 35 & 75 & 15 & 86 & 30 \\
\hline N. catarrhalis & 10 & 79 & 0 & - & 15 \\
\hline E. coli & 0 & - & 0 & - & 0 \\
\hline
\end{tabular}

* Average of 2 to 4 experimental values. The $60^{\circ}$ and $75^{\circ}$ incubations in $0.12 \mathrm{M}-\mathrm{PB}$ were carried out in free solution and assayed on hydroxyapatite. The reactions at $67^{\circ}$ in $3 \times \mathrm{SSC}$ utilized unlabelled DNA immobilized on $25 \mathrm{~mm}$. nitrocellulose filters.

$\dagger \mathrm{Tm}=$ temperature at which $50 \%$ of the DNA is denatured.

$\ddagger$ Homologous $N$. meningitidis reassociation was arbitrarily designated $100 \%$. Relatedness is expressed as \% relative to the homologous DNA reaction. The homologous reaction at $60^{\circ}$ in PB gave approximately $85 \%$ reassociation; at $75^{\circ}$ in $\mathrm{PB}, 75-80 \%$; and $67^{\circ}$ in $3 \times \mathrm{SSC}$, approximately $60 \%$.

Little or no difference was observable in the thermal elution midpoint (Tm) obtained from reaction products obtained at $60^{\circ}$ or $75^{\circ}$ involving homologous Neisseria meningitidis DNA fragments. Similarly, thermal elution mid-points from reactions involving the closely related DNA of $N$. meningitidis, $N$. gonorrhoeae and strain $\mathrm{z}$ were close to identical at both incubation temperatures. Alternatively, the marked decreases in duplex formation in $N$. meningitidis $-N$. sicca and $N$. meningitidis $-N$. flava reactions at $75^{\circ}$ was accompanied by marked increases in the corresponding elution mid-points.

Relationships between Neisseria meningitidis and the other Neisseria species. It is clear from Table I that these Neisseria species fall into three main groups on the basis of DNA relatedness. First are the species normally associated with disease, $N$. meningitidis, $N$. gonorrhoeae, and strain $\mathrm{z}$. The second group contains species generally considered 'non-pathogenic' represented by $N$. sicca and $N$. flava. The third group has little relationship to the other Neisseria tested and is represented in this study by N. catarrhalis.

The specificity of the DNA reassociation reaction was clearly increased at the higher incubation temperature. Figure I shows thermal elution profiles of interspecies DNA 


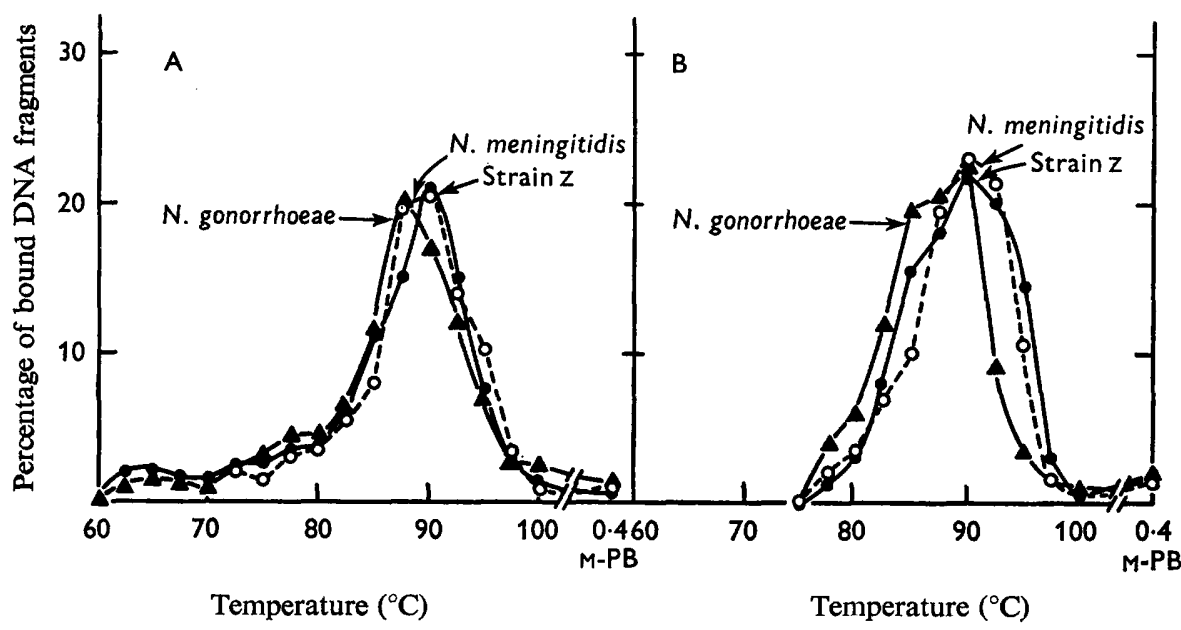

Fig. I (A). Thermal elution profiles of reassociated DNA duplexes formed between pathogenic Neisseria at $60^{\circ} .0 \cdot 1 \mu \mathrm{g}$ samples of single-stranded, ${ }^{32} \mathrm{P}$-labelled Neisseria menigitidis DNA fragments were incubated with approximately $500 \mu \mathrm{g}$. of unlabelled single-stranded DNA from $N$. meningitidis, $N$. gonorrhoeae or strain $z$. (B). Thermal elution profiles of reassociated DNA duplexes formed between pathogenic Neisseria at $75^{\circ}$. Reactions are identical to those in (A) except for incubation temperature.

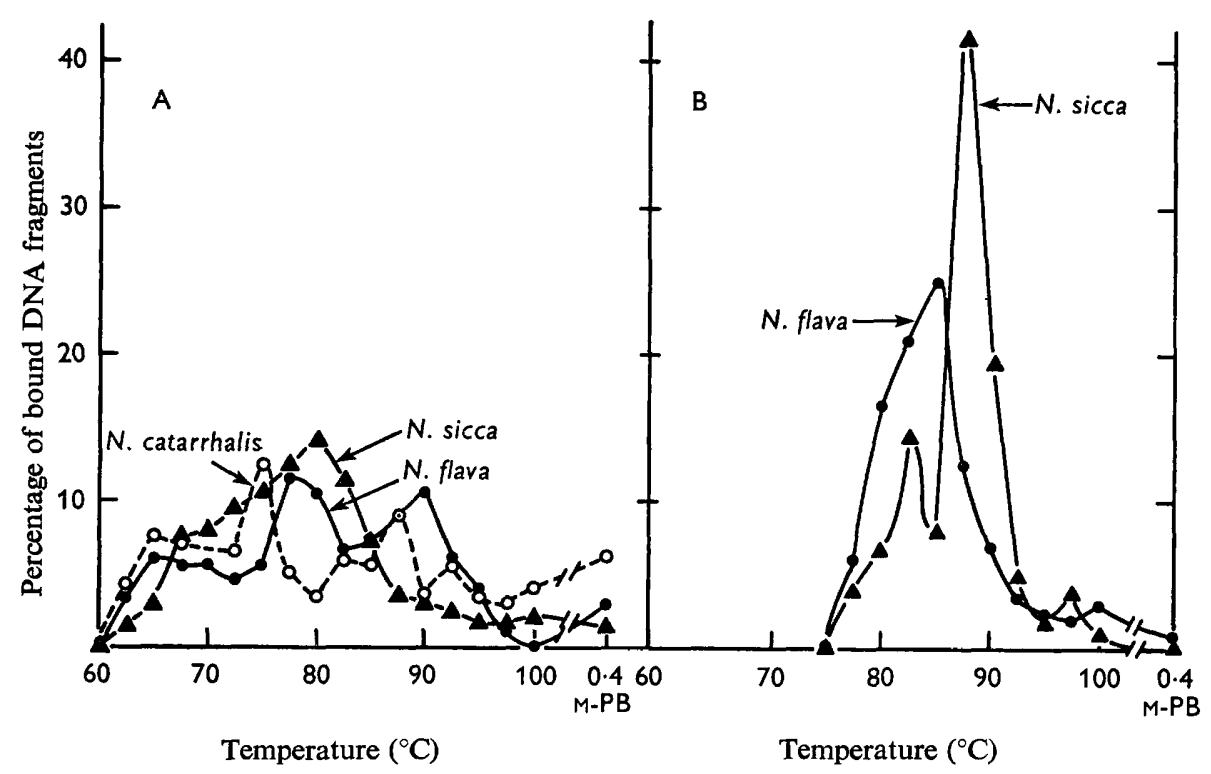

Fig. 2. (A) Thermal elution profiles of reassociated DNA duplexes formed between Neisseria meningitidis and non-pathogenic Neisseria species at $60^{\circ} .0 \cdot 1 \mu \mathrm{g}$. samples of single-stranded, ${ }^{32}$ P-labelled $N$. meningitidis DNA fragments were incubated with approximately $500 \mu \mathrm{g}$. of unlabelled, single-stranded DNA from $N$. flava, $N$. sicca and $N$. catarrhalis. (B) Thermal elution profiles of reassociated DNA duplexes formed between Neisseria meningitidis and non-pathogenic Neisseria species at $75^{\circ}$. Reactions are identical to those in (A) except for incubation temperature. No observable reaction took place between $N$. meningitidis and $N$. catarrhalis at $75^{\circ}$ (see Table I). 
duplexes from group I when the incubations were carried out at $60^{\circ}$ (Fig. I $a$ ) and $75^{\circ}$ (Fig. $\mathrm{I} b$ ) in $0.12 \mathrm{M}-\mathrm{PB}$. The profiles are sharp and tend towards a Gaussian distribution at both incubation temperatures. In both cases, the $\mathrm{Tm}$ of these interspecies DNA duplexes was within one or two degrees of that exhibited by a homologous $N$. meningitidis reaction. ( $\mathrm{Tm}=$ temperature of which $50 \%$ of the DNA is denatured.)

In contrast, Fig. 2 shows thermal elution profiles obtained from reactions between $N$. meningitidis and members of groups 2 and 3. The profiles from the $60^{\circ}$ (Fig. 2a) incubation were very broad and the Tm was depressed as much as $13^{\circ}$ below that of reassociated $N$. meningitidis DNA. The greater specificity of the duplexes formed at $75^{\circ}$ (Fig. $2 b$ ) is shown by the comparative sharpness and the greatly increased thermal stability of profiles obtained from reactions carried out at the higher temperature. Where no interspecies polynucleotide sequences exist with a stability approaching that of $N$. meningitidis DNA, as is apparently the case with $N$. catarrhalis, no DNA duplexes were detectible by the more selective criterion.

To insure reaction specificity, a control DNA from Escherichia coli was included in each of these experiments. Although its base composition is similar to that of $N$. meningitidis, 50 mole $\%$ guanine + cytosine $(\mathrm{G}+\mathrm{C})$, no relationship was detected between the DNA of $N$. meningitidis and $E$. coli, at any of the three incubation temperatures used.

\section{DISCUSSION}

The optimal temperature for reassociation of denatured DNA free in solution is some $25^{\circ}$ below its Tm (Marmur \& Doty, 1962). The Tm for Neisseria meningitidis DNA is about $88^{\circ}$ in $0.12 \mathrm{M}-\mathrm{PB}$ and about $93^{\circ}$ in $3 \times \mathrm{SSC}$. Therefore, reactions carried out at $60^{\circ}$ in $0.12 \mathrm{M}-\mathrm{PB}$ and at $67^{\circ}$ in $3 \times \mathrm{SSC}$ closely approximate optimal conditions for reassociation. A $75^{\circ}$ incubation temperature for reactions in $0.12 \mathrm{M}-\mathrm{PB}$ constitutes a highly stringent criterion for reassociation in the Neisseria, as evidenced by a $5-8 \%$ decrease in homologous $N$. meningitidis DNA duplex formation. The use of stringent incubation conditions allows the formation of only those interspecies DNA duplexes that exhibit a high degree of thermal stability. It seems likely that these stable interspecies duplexes reflect extensive base sequence similarity between organisms. Similarly, duplexes that exhibit a $\operatorname{Tm} 10^{\circ}$ to $25^{\circ}$ below the $\mathrm{Tm}$ of homologous $N$. meningitidis DNA (Fig. 2) and which are not formed at $75^{\circ}$ may be assumed to contain a significant proportion of unpaired nucleotide bases.

An alternative explanation for decreased stability in interspecies DNA duplexes is that the related sequences contain a preferentially high percentage of adenine (A) + thymine (T) base pairs. This explanation is considered unlikely because bacterial DNA usually shows a sharp and unimodal thermal melting transition indicative of a Gaussian distribution of $\mathrm{G}+\mathrm{C}$ centred around the mean base composition. In the $N$. meningitidis$N$. sicca reaction (Table I), and in several interspecies enterobacterial DNA reactions (Brenner \& Cowie, I968; D. J. Brenner \& S. Falkow, unpublished observations), at least $75 \%$ of the duplexes (corresponding to up to $30 \%$ of the genome) formed at $60^{\circ}$ are lost in $75^{\circ}$ reaction. It is doubtful whether bacterial DNA with a mean 50 mole $\%$ $\mathrm{G}+\mathrm{C}$ contains such a large fraction of $\mathrm{A}+\mathrm{T}$-rich sequences.

This argument does not rule out a combination of unpaired bases and preferentially high $\mathrm{A}+\mathrm{T}$ containing duplexes as causative factors in reducing the $\mathrm{Tm}$. It has been reported (Brenner \& Cowie, 1968) that at least half of the diminished stability in 
Escherichia coli-Salmonella typhimurium duplexes is attributable to unpaired bases. Preliminary results using labelled E. coli DNA fractionated according to base composition and reacted with $S$. typhimurium DNA give no indication of increased interspecies reaction when labelled A+T-rich fragments are used (D. J. Brenner, unpublished observation). This question remains to be answered directly for the Neisseria reactions.

The existence of three subgroups within the genus Neisseria, based on DNA relatedness, as suggested earlier (Kingsbury, 1967), is firmly supported by the present data on interspecies duplex stability. The pathogenic species tested are very closely related and form stable interspecies hybrids. Reciprocal experiments using labelled strain z DNA and unlabelled $N$. meningitidis also give an approximate value of $90 \%$ relative relatedness $\left(67^{\circ}, 3 \times\right.$ SSC) $(D$. T. Kingsbury, unpublished observation). The coincidence of the reciprocal values rules out the possibility that strain $\mathrm{z}$ is a deletion mutant of $N$. meningitidis. Hoyer \& McCullough (1968) noted even higher relatedness in Brucella species. It is tempting to speculate that the apparent conservation of nucleotide sequences seen in both of these pathogenic genera is the result of selection pressures resulting from obligate host-parasite interaction.

The degree of relatedness among the bulk of non-pathogenic Neisseria species is not nearly as high as that of the pathogens (Kingsbury, I967). The stability patterns in nonpathogenic interspecies duplexes remain to be investigated. The low degree of relatedness and lack of stable interspecies duplexes between Neisseria catarrhalis and $N$. meningitidis is not surprising in view of the low $\mathrm{G}+\mathrm{C}$ of $N$. catarrhalis. Catlin \& Cunningham (196I) found $N$. catarrhalis strains with $\mathrm{G}+\mathrm{C}$ percentages ranging from $40 \cdot 7$ to $44 \cdot 6$. These authors suggested that the $N$. catarrhalis strains formed a group unto themselves.

The recent work of Henriksen \& Bøvre (1968), suggesting that Neisseria meningitidis, $N$. gonorrhoeae, $N$. sicca and $N$. flava may be variants of the same species, is not supported by DNA reassociation data.

We are grateful to Dr R. J. Britten, Department of Terrestrial Magnetism, Carnegie Institution of Washington, for allowing us to use his pressure cell for shearing DNA.

The opinions or assertions contained herein are those of the authors and are not to be construed as official or reflecting the views of the Navy Department or the Naval service at large.

This investigation was supported by the Bureau of Medicine and Surgery, Navy Department, Research Tasks M 4305.01 . 1008 and MR 005.09.0010.

\section{REFERENCES}

BrenNeR, D. J. \& CowIE, D. B. (1967). Qualitative"aspects of microbial DNA duplexes. Yb. Carnegie Instn Wash. 66, 106.

BRENNER, D. J. \& CowIE, D. B. (I968). Thermal stability of Escherichia coli-Salmonella typhimurium deoxyribonucleic acid duplexes. J. Bact. 95, 2258.

BrenNer, D. J., Martin, M. A. \& Hoyer, B. H. (I957). Deoxyribonucleic acid homologies among some bacteria. J. Bact. 94, 486.

Britten, R. J. \& KohNE, D. E. (1966). Nucleotide sequence repetition in DNA. Yb. Carnegie Instn Wash. $65,78$.

Catlin, B. W. \& Cunningham, L. S. (1961). Transforming activities and base contents of deoxyribonucleate preparations from various Neisseriae. J. gen. Microbiol. 26, 303. 
Heberlein, G. T., DE Ley, J. \& TiJTGat, R. (1967). Deoxyribonucleic acid homology and taxonomy of Agrobacterium, Rhizobium and Chromobacterium. J. Bact. 94, I16.

Henriksen, S. D. \& BøVRe, K. (1968). The taxonomy of the genera Moraxella and Neisseria. J. gen. Microbiol. 5I, 387.

HoYeR, B. H. \& MCCULLOUGH, N. B. (I968). Polynucleotide homologies of Brucella deoxyribonucleic acids. J. Bact. $95,444$.

Johnson, J. L. \& ORDAL, E. J. (1968). Deoxyribonucleic acid homology in bacterial taxonomy: effect of incubation temperature on reaction specificity. J. Bact. 95, 893 .

KINGSBURY, D. T. (1966). Bacteriocin production by strains of Neisseria meningitidis. J. Bact. 91, 1696.

KingsBURY, D. T. (1967). Deoxyribonucleic acid homologies among species of the genus Neisseria. J. Bact. 94, 870 .

KINGSBURY, D. T. \& DUNCAN, J. F. (1967). Use of exogenous adenine to label the nucleic acids of wild-type Neisseria meningitidis. J. Bact. 94, 1262.

MARMUR, J. \& DotY, P. (1962). Determination of the base composition of deoxyribonucleic acid from its thermal denaturation temperature. J. molec. Biol. 5, I09.

MARTIN, M. A. \& HOYER, B. H. (1966). Thermal stabilities and species specificities of reannealed animal deoxyribonucleic acids. Biochemistry 5, 2706.

MCCARTHY, B. J. \& Bolton, E. T. (1963). An approach to the measurement of genetic relatedness among organisms. Proc. natn. Acad. Sci. U.S.A. 50, 156.

Mryazawa, Y. \& Thomas, C. A. (1965). Composition of short segments of DNA molecules. J. molec. Biol. II, 223.

SLATERUS, K. W. (I961). A serological typing of meningococci by means of micro-precipitation. Antonie van Leeuwenhoek 21, 305. 